\title{
Transcript Profiles in Sugar Beet Genotypes Uncover Timing and Strength of Defense Reactions to Cercospora beticola Infection
}

\author{
Fridtjof Weltmeier, ${ }^{1}$ Anja Mäser, ${ }^{1}$ Andreas Menze, ${ }^{2}$ Steffen Hennig, ${ }^{3}$ Martina Schad, ${ }^{3}$ Frank Breuer, ${ }^{2}$ \\ Britta Schulz, ${ }^{2}$ Bernd Holtschulte, ${ }^{2}$ Reinhard Nehls, ${ }^{1}$ and Dietmar J. Stahl ${ }^{1}$ \\ ${ }^{1}$ PLANTA Angewandte Pflanzengenetik und Biotechnologie GmbH, Grimsehlstraße 31, D-37555 Einbeck, Germany; ${ }^{2} \mathrm{KWS}$ \\ SAAT AG, Grimsehlstraße 31, D-37555 Einbeck, Germany; ${ }^{3}$ maGenes GmbH, Robert-Roessle-Straße 10, D-13125 Berlin, \\ Germany
}

Submitted 3 September 2010. Accepted 26 February 2011.

\begin{abstract}
Cercospora leaf spot disease, caused by the fungus Cercospora beticola, is the most destructive foliar disease of sugar beet (Beta vulgaris) worldwide. Despite the great agronomical importance of this disease, little is known about its underlying molecular processes. Technical resources are scarce for analyzing this important crop species. We developed a sugar beet microarray with 44,000 oligonucleotides that represent 17,277 cDNAs. During the four stages of $C$. beticola-B. vulgaris interactions, we profiled the transcriptional responses of three genotypes: susceptible, polygenic partial resistance, and monogenic resistant. Similar genes were induced in all three genotypes during infection but with striking differences in timing. The monogenic resistant genotype displayed strong defense responses at 1 day postinoculation (dpi). The other genotypes displayed defense responses in a later phase $(15 \mathrm{dpi})$ of the infection cycle. The partially resistant genotype displayed a strong defense response in the late phase of the infection cycle. Furthermore, the partially resistant genotype expressed pathogenrelated transcripts that the susceptible genotype lacked. These results indicate that resistance was achieved by the ability to mount an early defense response, and partial resistance was determined by additional defense and signaling transcripts that allowed effective defense in the late phase of the infection cycle.
\end{abstract}

Cercospora leaf spot disease, caused by the imperfect filamentous fungus Cercospora beticola, has been documented for over a century. It is the most destructive foliar disease of sugar beet (Beta vulgaris) worldwide (Smith and Ruppel 1974), This disease results in reduced yield and quality of sugar beet. Control by extensive fungicide application has incurred added cost and has selectively promoted fungicide-tolerant $C$. beticola strains. Despite its great economical importance, little is known about the molecular basis of the B. vulgaris-C. beticola interaction.

C. beticola is a hemibiotrophic fungus, with biotrophic and necrotrophic phases. One sporulation cycle under field conditions lasts approximately 12 days. Approximately 3 to 4 days

Corresponding author: D. J. Stahl; Telephone: +49-5561-311735; Fax: +49-5561-311243; E-mail: d.stahl@kws.com

* The $e$-Xtra logo stands for "electronic extra" and indicates that four supplementary figures and three supplementary tables are published online. after inoculation, the fungus enters the host through open stomata (Rathaiah 1977). After penetration, fungal hyphae grow intercellularly and colonize the leaf parenchyma tissue in an asymptomatic manner (Feindt et al. 1981; Steinkamp et al. 1979). The final, necrotrophic phase is characterized by the formation of necrotic lesions, resulting in leaf spots, the typical sign of this disease. Unlike other leaf pathogens that necrotize from pinpoint lesions and expand outward, lesions produced by C. beticola involve the near-simultaneous collapse of cells in an area many millimeters in diameter. The necrotized tissue becomes the site of conidiophore and conidial development. Although lesions can expand after the initial tissue collapse, the increase in necrotic area on the leaf surface is due primarily to an increase in the number of lesions. The fungus $C$. beticola produces different phytotoxins in order to necrotize the cells in the vicinity of the branched hyphae, including the photoactivated, nonspecific toxin cercosporin. Cercosporin produces singlet oxygen species and superoxide and has been well studied for over two decades (Daub and Ehrenshaft 2000). In addition to cercosporin, $C$. beticola produces other classes of phytotoxins, including the beticolins, which have also been shown to debilitate normal plant cell function (Goudet et al. 1998).

Currently, resistance to $C$. beticola in the field is quantitatively inherited in sugar beet (Koch and Jung 2000). Quantitative trait loci (QTL) of $C$. beticola resistance have been mapped to four (Nilsson et al. 1999; Setiawan et al. 2000) and six of the nine sugar beet chromosomes (Schäfer-Pregl et al. 1999). B. vulgaris cultivars with quantitative resistance exhibit reduced lesion size, reduced lesion numbers on infected leaves, and reduced conidial production per unit area of lesion (Rossi et al. 1999). Apart from the quantitative resistance determined by QTL, resistance can be race specific, determined by a single locus. Although this is atypical for sugar beet and $C$. beticola, one exception of potential race-specific resistance has been reported: the $C$. beticola isolate $\mathrm{C} 2$ can be discriminated from isolate $\mathrm{C} 1$ by its ability to induce small lesions called "fleck reactions" on sugar beet germplasms that harbor the single dominant $C b$ resistance $(R)$ gene (Whitney and Lewellen 1976). This reaction is reminiscent of a hypersensitive response, characteristic of monogenic resistance mediated by a single locus. Furthermore, isolate $\mathrm{C} 2$ exhibits higher virulence than isolate $\mathrm{C} 1$ on sugar beet cultivars that lack the $C b$ gene. However, the $C b R$ gene and the corresponding avirulence $(A v r)$ gene of isolate $\mathrm{C} 2(\mathrm{AvrCb})$ have not been isolated.

Currently, the molecular mechanisms of the B. vulgaris host response that lead to monogenic or polygenic resistance have 
not been well studied. Some pathogenesis-related (PR) proteins with chitinase and glucanase activity have been identified (Gottschalk et al. 1998; Nielsen et al. 1993). However, little is known about the impact of $C$. beticola infection on the $B$. vulgaris transcriptome.

During the last decade, microarrays have become a powerful tool for simultaneously probing the expression levels of thousands of genes. Biological processes are reflected to a high degree by changes in the transcript abundance of involved genes. The potential of capturing genome-wide transcriptional changes allows a better understanding of the molecular mechanisms underlying biological processes. Furthermore, complex traits such as polygenic partial resistance can be analyzed on a genomic scale. In the analysis of host-pathogen interactions, transcript profiling has been established as a particularly valuable tool that allows a system-wide approach for identifying unifying themes and unique features (Wise et al. 2007). Microarray profiling has been applied for most major crop species, such as rice and wheat. The resulting important scientific discoveries are documented in hundreds of research articles, many with high scientific impact. However, no commercial microarray is available for $B$. vulgaris.

To take advantage of microarray-based genome-wide expression profiling for the sugar beet, we developed a 4 by 44,000 oligonucleotide-based sugar beet microarray with the ability to detect the transcripts of 17,277 genes. We used this microarray to determine the transcriptional changes that underlie the interactions between the sugar beet and $C$. beticola during the entire infection cycle, from conidia germination to lesion formation. Furthermore, to elucidate molecular processes underlying the different forms of resistance, we compared the transcriptional responses associated with susceptible, polygenic partially resistant, and monogenic resistant interactions. Apart from identifying the general characteristics of the defense of $B$. vulgaris in response to $C$. beticola, we were able to demonstrate a surprisingly rapid defense response during the monogenic resistant interaction. In contrast, the polygenic partial resistance was characterized by much more subtle differences involving the strength of the defense response and the pool of available defense genes.

\section{RESULTS}

\section{Development of a sugar beet microarray.}

In order to develop a sugar beet microarray, 17,277 nonredundant cDNA clones were isolated with the oligonucleotide fingerprinting (ofp) approach, as described previously (Herwig et al. 2002). cDNA clones were isolated from untreated and $C$. beticola-infected sugar beet leaves to include transcripts expressed only after pathogen attack. Based on the sequences of these clones, an optimized multiplex array was designed with a preselection strategy (Fig. 1). In the first (preselection) round, a highresolution microarray with 244,000 60-mer oligos was carefully constructed according to the following rules: i) oligos had to be unique tags for the respective cluster sequence and ii) the oligo density per cluster was adjusted to be approximately constant for all clusters. The resulting 244,000 oligo (244K) microarray was hybridized with a complex pool of sugar beet RNAs labeled with cyanine dye 3 (cy3) and sugar beet genomic DNA labeled with cy5. The best-performing oligos from each cluster were identified and the minimal number of oligos per cluster was selected. The final outcome was an optimized array which, in contrast to pure in silico design procedures such as eArray, used hybridization patterns to identify oligos that performed optimally. The 17,277 different genes represented on this sugar beet microarray were functionally annotated with the PEDANT software suite (Frishman et al. 2001).
Experimental design-monogenic versus polygenic resistance.

The aim of this study was to elucidate the transcriptional host response of $B$. vulgaris induced during a $C$. beticola infection. Furthermore, we compared the transcriptional changes associated with susceptible, polygenic, or monogenic resistance of $B$. vulgaris to $C$. beticola. The B. vulgaris genotype K31 has displayed resistance in field tests and is used as an example of polygenic resistance. The genotype FC702/2 carries the $C b$ gene (Whitney and Lewellen 1976) and confers resistance to the $C$. beticola isolate $\mathrm{C} 2$. The FC702/2-C2 interaction serves as an example of monogenic resistance. In this study, both types of resistance were compared with transcriptional changes observed in the standard, susceptible genotype, D108 (Fig. 2A).

Inoculation was performed in the greenhouse with the two different $C$. beticola isolates, C1 and C2 (Whitney and Lewellen 1976). Isolate $C 1$ is similar to the $C$. beticola isolates commonly found in the field. The monogenic resistance of genotype FC702/2, which carries the $C b$ gene, is specific for the $C$. beticola isolate $\mathrm{C} 2$; thus, infection with the two different isolates allowed differentiation between the transcriptional changes generally typical for the genotype FC702/2 and those specific for monogenic resistance. As a control treatment, a mock inoculation was performed. We analyzed six different time points throughout the infection process with four independent biological replicates. Hence, three genotypes $\times$ three treatments $\times$ six time points $\times$ four biological replicates, totaling 216 microarrays, were analyzed.

\section{Microscopic observation of the infection process.}

Infection by Cercospora spp. lasts several days and can be divided into several phases. The first phase lasts 3 days postinoculation (dpi) and is characterized by conidia germination and hyphal growth on the leaf surface. The second phase is biotrophic; it starts with the penetration of stomata at 3 to 4 dpi (Schmidt et al. 2008) and ends with an asymptomatic colonization of the tissue (Feindt et al. 1981). The third, final, necrotrophic phase is characterized by the formation of necrotic lesions (approximately $15 \mathrm{dpi}$ ).

To correlate stages of the infection process with transcriptional profiles, the infection progress was monitored during sample collection. Leaf discs were taken from the sampled material used for expression profiling, stained with lactophenol aniline blue for detection of conidia and hyphae, and analyzed microscopically (Supplementary Table S1).

Most spores had germinated at $1 \mathrm{dpi}$. Germination rates and outgrowth were accelerated in the more aggressive isolate C2. The monogenic resistant interaction was associated with slower outgrowth. Penetration of stomata took place from 3 dpi (isolate C2) to 4 dpi (isolate C1). Penetration was also observed in the monogenic interaction but at a noticeably slower rate. At $15 \mathrm{dpi}$, necrosis formation began to be visible on inoculated plants but was more clearly visible on C2-inoculated plants. This time frame is consistent with one sporulation cycle under field conditions. At $21 \mathrm{dpi}$, all except the monogenic resistance leaves showed strong lesion formation (Fig. 2A).

Based on these observations, samples collected at $0,1,3,4$, 6 , and 15 dpi were used for RNA extraction and expression profiling. These samples represented the stages of germination, penetration of stomata, parenchyma colonization, and the beginning of necrosis formation.

\section{Quantification of C. beticola biomass during the infection time course.}

Our sugar beet microarray contained 27 probe sets that detected $C$. beticola transcripts with signals well above background. These probe sets were employed to determine the fungal 
biomass of Cercospora spp. in the analyzed samples. Of the 27 C. beticola transcripts, 4 encoded ribosomal proteins that were considered housekeeping genes with stable expression. We used these four transcripts to determine $C$. beticola biomass in order to avoid artifacts caused by differential expression of other transcripts during the infection cycle. However, an analysis with the median of all 27 transcripts gave highly similar results.

With this approach, we determined the growth of Cercospora spp. during the course of infection from the time of inoculation through 15 dpi (Fig. 2B). A significant increase in Cercospora biomass was detected only between 6 and 15 dpi. Growth of Cercospora isolate C2 was approximately 10-fold higher than growth of isolate $\mathrm{C} 1$, consistent with its increased aggressiveness (Whitney and Lewellen 1976) and the observed disease symptoms. As expected, in the monogenic resistance interaction, Cercospora isolate $\mathrm{C} 2$ showed no significant growth (i.e., no increase in fungal biomass). In our hands, at $15 \mathrm{dpi}$, Cercospora spp. growth in the polygenic resistant $\mathrm{K} 31$ genotype exhibited an approximately $50 \%$ reduction in fungal biomass compared with that observed in the susceptible genotype D108. This reduction was independent of the Cercospora isolate used for inoculation.

Analysis of global $B$. vulgaris gene expression during $C$. beticola infection.

Leaf samples were collected at $0,1,3,4,6$, and 15 dpi in four biological replicates, and changes in gene expression were calculated relative to mock-inoculated plants. An average of approximately $85 \%$ of the oligos on the array exhibited significant signals.

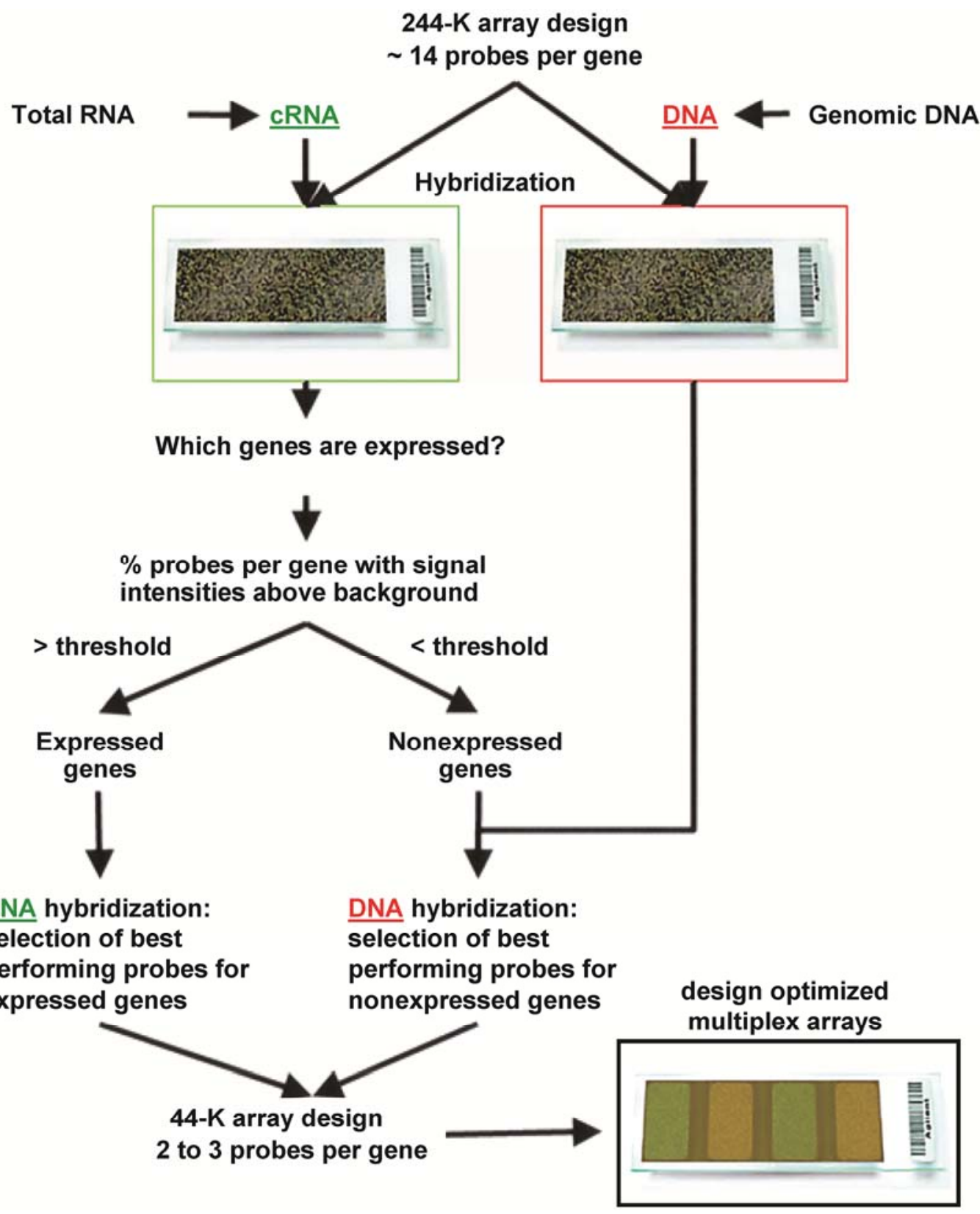

Fig. 1. Flow chart of the microarray design process. The array design was based on sequences of 17,277 Beta vulgaris cDNA clones. In a preliminary, large 244,000 oligo array design, each gene was tiled with a maximum number of probes (approximately 14 probes per gene). Complex total RNA and genomic DNA samples were hybridized on this preliminary array. For each gene, the best-performing probes were selected, based on RNA hybridization for expressed genes and on DNA hybridization for nonexpressed genes. Using this approach, the number of oligos was reduced to two to three best-performing oligos per gene, leading to the final 44,000 oligo design. 
The transcriptomes of analyzed sugar beet genotypes were found to be surprisingly divergent. A principle component analysis (PCA) and a hierarchical clustering analysis (HCA) revealed high variations between genotypes (Supplementary
Fig. S1). The major differences were found between D108 and the resistant genotypes K31 and FC702/2. The PCA and the HCA showed that, at $15 \mathrm{dpi}$, the two nonresistant genotypes infected with the more virulent isolate $\mathrm{C} 2$ were clearly sepa-
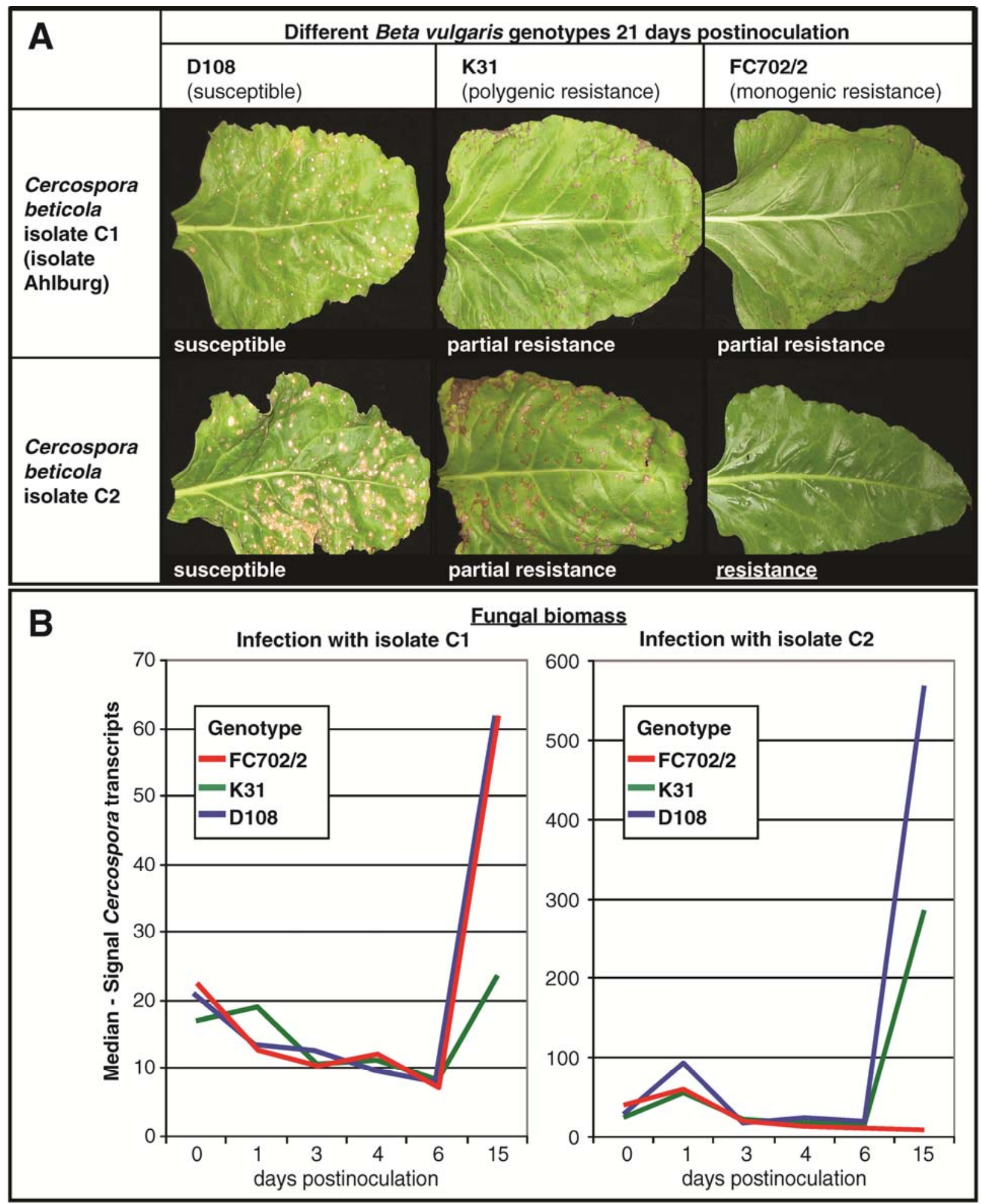

Fig. 2. Experimental design. A, Phenotypes of Beta vulgaris genotypes without or with polygenic or monogenic resistance are shown 21 days postinoculation (dpi). After inoculation with the Cercospora isolate $\mathrm{C} 1$, all genotypes displayed necrotic lesions, which are most pronounced on the susceptible genotype D108. Disease phenotypes after C2 infection were more severe than after C1 infection, corresponding to the higher virulence of the C2 isolate. The genotype FC702/2 (lower right side) carried monogenic resistance and displayed no disease symptoms at 21 dpi when infected with strain C2. The combination of three different $B$. vulgaris genotypes and two Cercospora beticola isolates permitted the profiling of transcriptional changes in two susceptible, three partially resistant, and one resistant interaction. B, Estimation of the fungal biomass. The mean signal intensity of four C. beticola ribosomal protein transcripts detected on our sugar beet microarray was calculated at each time point. Independent of the $C$. beticola isolate, at $15 \mathrm{dpi}$, the fungal biomass was approximately 50\% lower in the partially resistant genotype K31 (green line) compared with the susceptible genotype D108 (blue line). 
rated from the other samples, indicating a high level of differential expression.

The differentially expressed genes were then filtered with the following criteria: a fold change $>3$ and a $P$ value $<0.001$, based on separate $t$ tests for each sample. To ensure that the numbers of differentially expressed transcripts remained comparable between the analyzed conditions, a false discovery rate was not applied. However, based on the approach of Benjamini and Hochberg (1995), we estimated that the 130 differentially expressed transcripts identified for the monogenic resistant interaction at $1 \mathrm{dpi}$ had an approximate false discovery rate of 0.03 . These selection criteria for differentially expressed genes can lead to false negatives. For example, PR protein 1 (PR-1; cluster000213.a1.2), a well-known marker for pathogen-induced gene expression, was induced both after infection with isolate $\mathrm{C} 1$ and after infection with isolate $\mathrm{C} 2$. However, with our stringent criteria, PR-1 expression was only statistically significant after the $\mathrm{C} 2$ infection. Thus, to distinguish the different sources of resistance from the susceptible interactions, we focused only on the most reliable differentially expressed genes. Expression profiles of samples taken directly after inoculation (0 dpi) were extremely noisy, probably due to diverse stresses connected with the inoculation procedure. Therefore, those samples were excluded from further analysis.

In total, 722 genes showed statistically significant differential expression in at least one of the conditions analyzed (Table 1). Among these, significant enrichment was observed for defense-related genes. Interestingly, most of the differentially expressed genes were upregulated. As expected, the highest numbers of differentially expressed genes were found at $15 \mathrm{dpi}$ in plants treated with the more aggressive isolate $\mathrm{C} 2$. In contrast to $\mathrm{C} 2$ infections, $\mathrm{C} 1$ infections, which were much less progressed at $15 \mathrm{dpi}$, resulted in only small numbers of differentially expressed genes. At $15 \mathrm{dpi}$ with isolate $\mathrm{C} 2$, the partially resistant genotype $\mathrm{K} 31$ exhibited $>1.5$-fold more differentially expressed genes than the susceptible genotype D108, although it had less Cercospora biomass.

In the genotype FC702/2, which carried the $C b R$ gene, at 15 dpi with isolate $\mathrm{C} 2$, differential gene expression was nearly undetectable (Table 1). This was expected, because no necrotic lesions were formed in this interaction. Furthermore, the absence of differentially expressed genes supported the assumption that the infection process ended at $15 \mathrm{dpi}$. In this genotype, no late transcriptional response was observed. Instead, a comparably strong response was observed at $1 \mathrm{dpi}$, where 130 differentially expressed transcripts were detected. This response was specific for the monogenic resistant interaction and was not observed in genotypes lacking the $C b$ gene.

To confirm the general reliability of our $44 \mathrm{~K}$ sugar beet microarray, we used quantitative reverse-transcription polymerase chain reaction (qRT-PCR) to validate the differential expression of selected genes identified in our experiments (Fig. 3). For validation, we chose genes that were highly in-

Table 1. Number of transcripts differentially expressed between plants inoculated with Cercospora spp. and plants mock inoculated at the given time points ${ }^{\mathrm{a}}$

\begin{tabular}{lrrcrc}
\hline Transcript & Day $\mathbf{1}$ & Day 3 & Day 4 & Day $\mathbf{6}$ & Day 15 \\
\hline FC702/2-C1 & 4 & 3 & 3 & 22 & 34 \\
FC702/2-C2 & 130 & 11 & 4 & 6 & 3 \\
K31-C1 & 4 & 12 & 2 & 1 & 8 \\
K31-C2 & 0 & 6 & 2 & 8 & 436 \\
D108-C1 & 4 & 2 & 1 & 5 & 31 \\
D108-C2 & 10 & 2 & 1 & 29 & 283 \\
\hline
\end{tabular}

${ }^{a}$ Cercospora and transposon transcripts have been removed. Selection criteria for differentially expressed transcripts were a $P$ value $<0.001$ and a fold change $>3$. duced either in the monogenic resistant interaction at $1 \mathrm{dpi}$ or in the other interactions at $15 \mathrm{dpi}$. The high accuracy of the expression data obtained with our microarray was verified for all genes analyzed by qRT-PCR. Interestingly, different PR genes that were highly induced at $15 \mathrm{dpi}$ in genotypes K31 and D108 did not reach induction maximum at $1 \mathrm{dpi}$ in the monogenic resistant interaction with genotype FC702/2. Rather, their maximum induction was slightly delayed to 3 or $4 \mathrm{dpi}$.

\section{Comparison of the transcriptional responses in the different interactions.}

To identify differences between the susceptible and monogenic resistant interactions, we compared genes that showed significant differential expression after infection with isolate $\mathrm{C} 2$. We compared genes that were differentially expressed at 1 dpi in genotype FC702/2 and those differentially expressed at 15 dpi in the other two genotypes. In total, 633 genes were significantly induced in at least one of these three conditions. Of the 571 genes induced at $15 \mathrm{dpi}$ in either the susceptible (D108) or the polygenic resistant (K31) interaction, 148 genes were found in both interactions (Fig. 4A). The genes not found in both groups were mostly induced in both interactions but failed to meet the $P$-value cutoff criteria in one interaction. However, some genes, including homologs of genes known to be involved in pathogen defense, had been induced only in the polygenic resistant genotype K31. We performed a correlation analysis of the fold-change induction values of the genes expressed in both groups, and we found that they were, indeed, highly correlated (correlation coefficient $=0.87$ ) (Fig. 4B). More importantly, although $C$. beticola growth was reduced in the polygenic resistant genotype, the induction factors in this genotype were, on average, twofold higher than in the susceptible interaction.

Next, we compared the transcriptional responses of the partially resistant and susceptible interactions that were observed in the late phase ( $15 \mathrm{dpi})$ to those observed in the monogenic resistance interaction at $1 \mathrm{dpi}$. Here, we expected different responses due to three factors: i) the monogenic versus polygenic basis of the response, ii) the different kinetics, and iii), in contrast to $15 \mathrm{dpi}$, at $1 \mathrm{dpi}$, the infection was not in the necrotrophic phase. However, we found significant overlap among the three groups. Despite our stringent significance criteria, over $50 \%$ of the 130 genes with significant regulation in monogenic resistance at 1 dpi were also significantly regulated in the partially resistant or susceptible interaction at $15 \mathrm{dpi}$ (Fig. 4A). Actually, this is even an underestimation of the similarity of both responses: Many of those genes which do not appear in the intersection of the Venn diagram were nevertheless co-regulated but failed to meet our stringent $P$-value or fold-change selection criteria in the interactions at 15 dpi. If we disregard this stringent selection criteria, 116 of the 130 genes with significant regulation in monogenic resistance are co-regulated in all three interactions (i.e., they are either induced in all three interactions or repressed in all three interactions) (Supplementary Table S2).

Only six genes displayed clear differences in regulation between the early and late responses. These were significantly repressed in monogenic resistance at $1 \mathrm{dpi}$ but were induced at $15 \mathrm{dpi}$ in the other interactions. Most of these genes (an f-box protein, an adenylyl cyclase-like protein, a glycine-rich protein, a kinase, and an aspartic proteinase) were involved in signal transduction processes. As mentioned above, a global analysis of expression profiles by PCA or HCA revealed major differences between the susceptible D108 and the resistant genotypes, K31 and FC702/2. With K-means clustering of expression profiles over all conditions, we identified a large cluster of transcripts that were present in the resistant genotypes but 
were not detected in the susceptible genotype (Fig. 5A). This was consistent with the separation of D108 in the global analysis of expression profiles. To identify genes that might be involved in the partial polygenic resistance of genotype K31, we searched for transcripts that were absent or expressed at very low levels in D108 but were expressed well above background and induced by the $C$. beticola infection in K31. We were able to identify four transcripts, all of which displayed high induci-

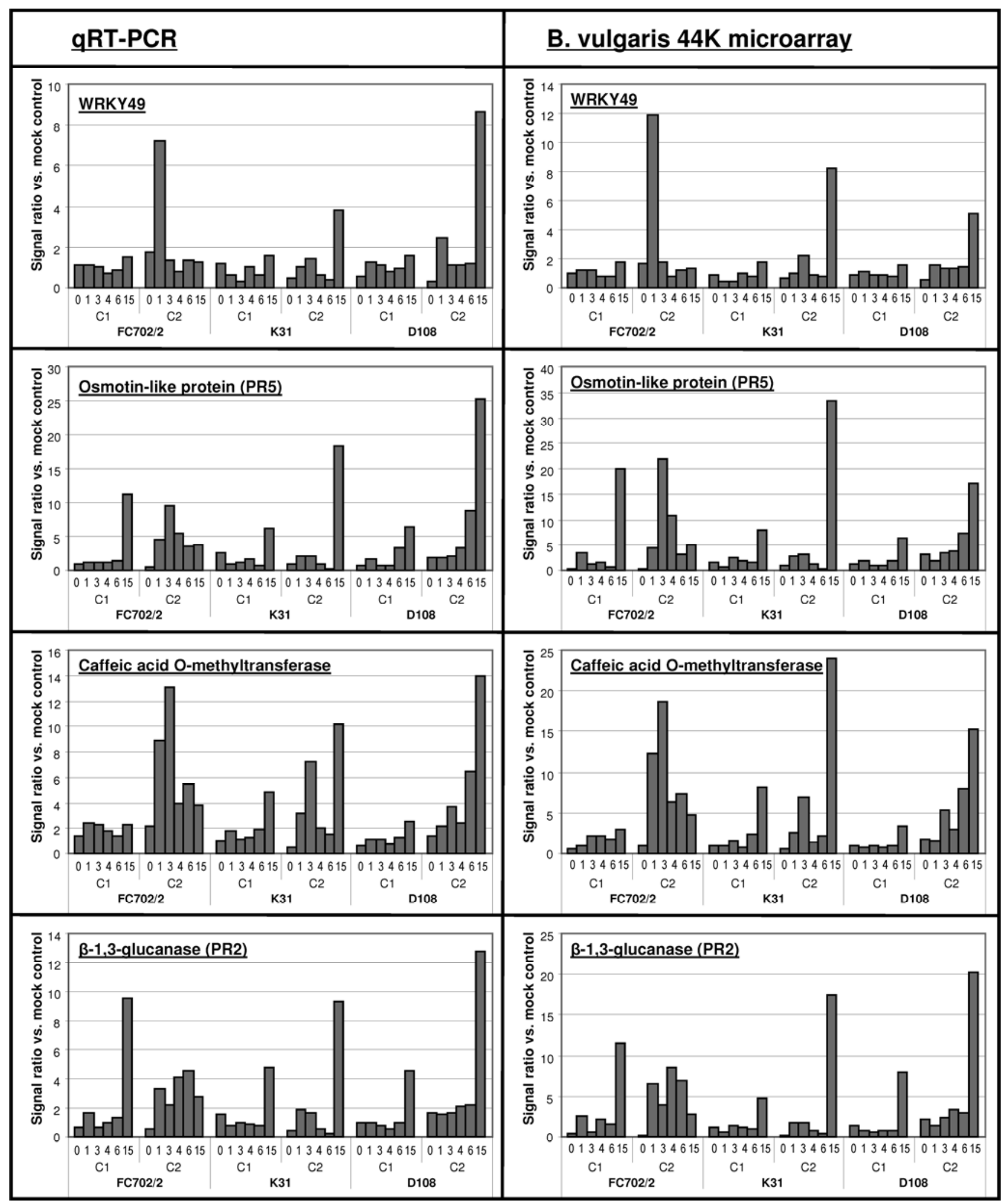

Fig. 3. Quantitative reverse-transcription polymerase chain reaction (qRT-PCR) validation of differential expression measured with the 44,000 oligo (44K) Beta vulgaris microarray. Differential expression of four selected Cercospora spp.-induced transcripts was validated over all time points, genotypes, and pathogens. Expression ratios relative to the mock controls were calculated for data retrieved from the microarray (right side) and by qRT-PCR (left side). Deviation between expression ratios detected by microarray and qRT-PCR were generally less than twofold, which is within the range of technical noise of qRT-PCR results. Therefore, expression levels measured by the $B$. vulgaris $44 \mathrm{~K}$ microarray were highly reproducible. 
bility specific for K31. Two of these genes, a putative receptor kinase (RLK) and an E3 ubiquitin-protein ligase, were involved in cell signaling; one was encoding an unidentified protein; and one was encoding a PR protein (Fig. 5B). The putative receptor kinase could be an interesting candidate contributing to resistance; therefore, we isolated the full-length cDNA and analyzed the expression of this gene by qRT-PCR (Supplementary Fig. S3). qRT-PCR analysis confirmed that this gene is expressed well above background and induced by the $C$. beticola infection in $\mathrm{K} 31$, whereas it is hardly expressed in the susceptible genotype D108. BLAST analysis of the full-length cDNA sequence identified a large number of RLK as closest homologs. However, the cDNA sequence itself includes nine leucine-rich repeats (LRR) but lacks the C-terminal kinase do-
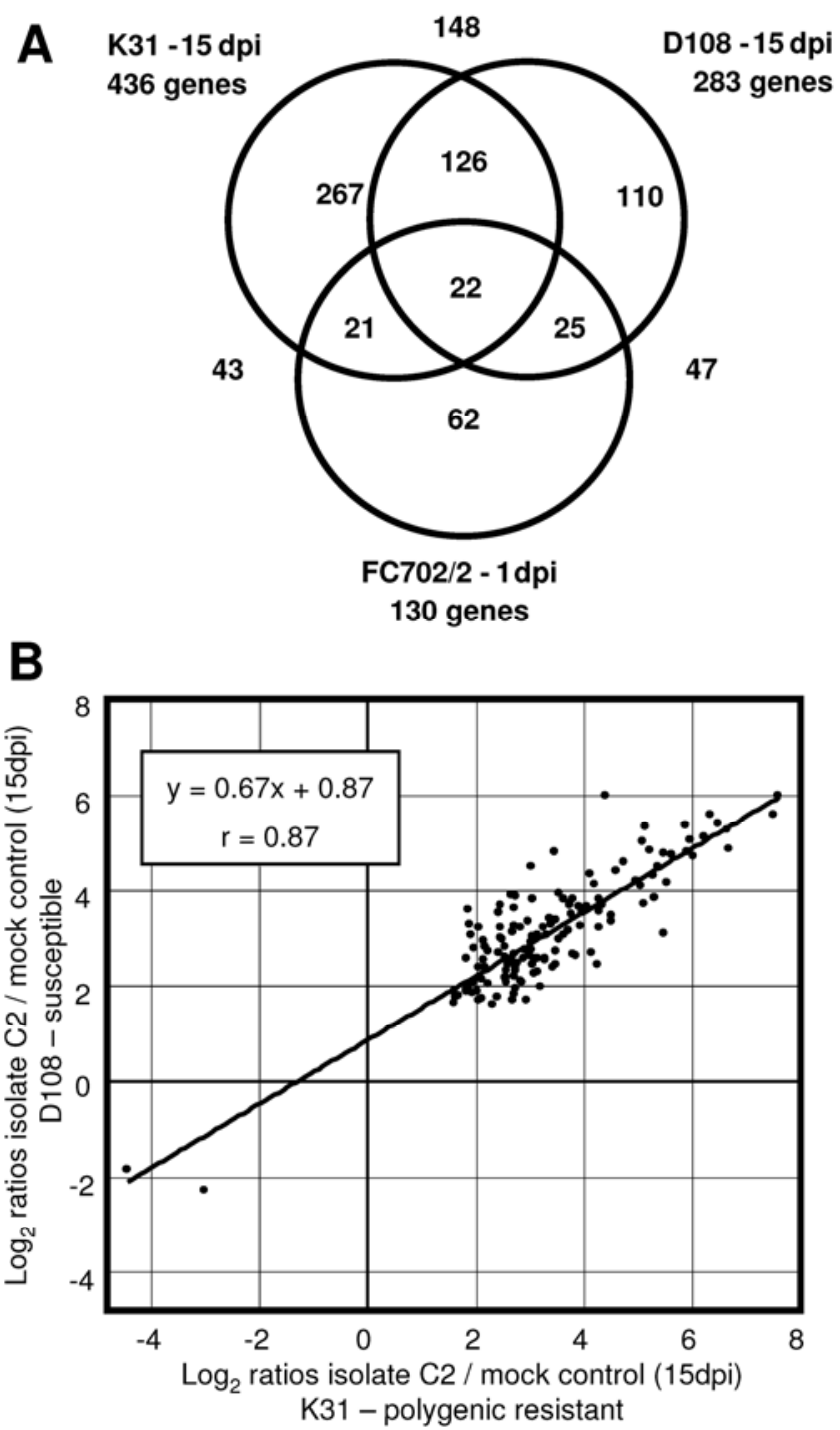

Fig. 4. Comparison of the different transcriptional responses. A, Venn diagram of differentially expressed genes induced in compatible and incompatible Beta vulgaris-Cercospora beticola interactions. Differentially expressed genes were selected based on a fold change $\geq 3$ and $P$ values $<0.001$ (633 genes in total). B, Differential gene expression at 15 days postinoculation (dpi) with isolate $\mathrm{C} 2$ in the polygenic resistant interaction correlated with that in the susceptible interaction. The $\log _{2}$ ratios of induction or repression versus the corresponding mock controls were calculated for genes with significant differential expression in both interactions. The differential expression was strongly correlated (correlation coefficient $=$ 0.87) but the average $\log _{2}$ ratios of induction (repression) in the polygenic resistant interaction were higher, as confirmed by regression analysis. This indicated a higher or faster induction of defense genes in K31. main; therefore, it encodes a receptor-like protein rather than a receptor like kinase.

Further signaling and PR genes were identified with increased inducible expression in K31 but their transcript levels were less prominently increased compared with D108 (data not shown).

\section{MapMan for functional classifications of differentially expressed genes.}

To assign transcriptional changes to cellular processes, we adapted the MapMan tool (Thimm et al. 2004) to our $44 \mathrm{~K}$ sugar beet array. A functional classification of the B. vulgaris transcripts was performed with the Mercator tool. Next, we identified functional categories that showed significant overrepresentation among the 633 genes that were differentially expressed at either $1 \mathrm{dpi}(\mathrm{FC} 702 / 2)$ or $15 \mathrm{dpi}$ (K31 and D108) with isolate $\mathrm{C} 2$. This was achieved by calculating the number of genes that represented a single class on the array and the number of genes from this class that showed differential expression. The ratio of these two values was taken as an indicator of over-representation of the functional class among differentially expressed genes. A hypergeometric distribution was used to calculate the statistical significance of the over-representation (Supplementary Table S3).

The categories that showed the most significant over-representation included biotic stress, receptor kinases, phenylpropanoid metabolism, WRKY transcription factors, and ethylene metabolism. These categories are known for their importance in pathogen defense, and their over-representation confirmed the validity of our data. To facilitate a comprehensive visualization of differential gene expression, we used MapMan to create a map of the functional classes that were significantly over-represented. Differential expression data from 1 and 15 dpi with isolate C2 were overlaid on this map (Fig. 6). This map clearly shows that the transcriptional responses at $1 \mathrm{dpi}$ included a considerable induction of defense genes and the activation of transport, secondary metabolism, and cell wall genes in the genotype FC702/2. In the other genotypes that lacked the $C b$ gene, almost no transcriptional response was detected at 1 dpi. Instead, we saw a similar response at 15 dpi.

A comparison of the individual functional categories showed similarities (e.g., in the induction of receptor kinases, calcium signaling, transcription factors, or ethylene and jasmonic acid [JA] metabolism). Almost no differential expression of salicylic acid (SA)-related genes was observed. The functional categories with distinct responses at 1 dpi compared with 15 dpi included glutathione- $S$-transferases (GST) in particular, and also carbohydrate $(\mathrm{CHO})$ metabolism and photosynthesis genes. All five of the GST that were only slightly induced or not induced at $1 \mathrm{dpi}$ in the monogenic resistance interaction showed high levels of induction at $15 \mathrm{dpi}$ in the other interactions. Furthermore, the repression of $\mathrm{CHO}$ metabolism and photosynthesis genes was also absent at $1 \mathrm{dpi}$ in the monogenic resistance and was only observed at $15 \mathrm{dpi}$ in the other interactions.

Finally, differential expression data from 1 and 15 dpi with isolate C1 were overlaid on this map (Supplementary Fig. S4). The same set of genes induced at $15 \mathrm{dpi}$ with isolate C2 was also induced with isolate $\mathrm{C} 1$, although lower levels of induction were observed and a smaller proportion of genes were induced. Most importantly, induction of the gene set in the genotype FC702/2 was observed at 15 , not 1 , dpi. This indicated that the induction at $1 \mathrm{dpi}$ in the FC702/2-C2 interaction was due to monogenic resistance and was not a genotype-specific effect.

\section{Comparison of induction levels.}

Although highly similar sets of genes were regulated in the different sugar beet-Cercospora spp. interactions, there were 

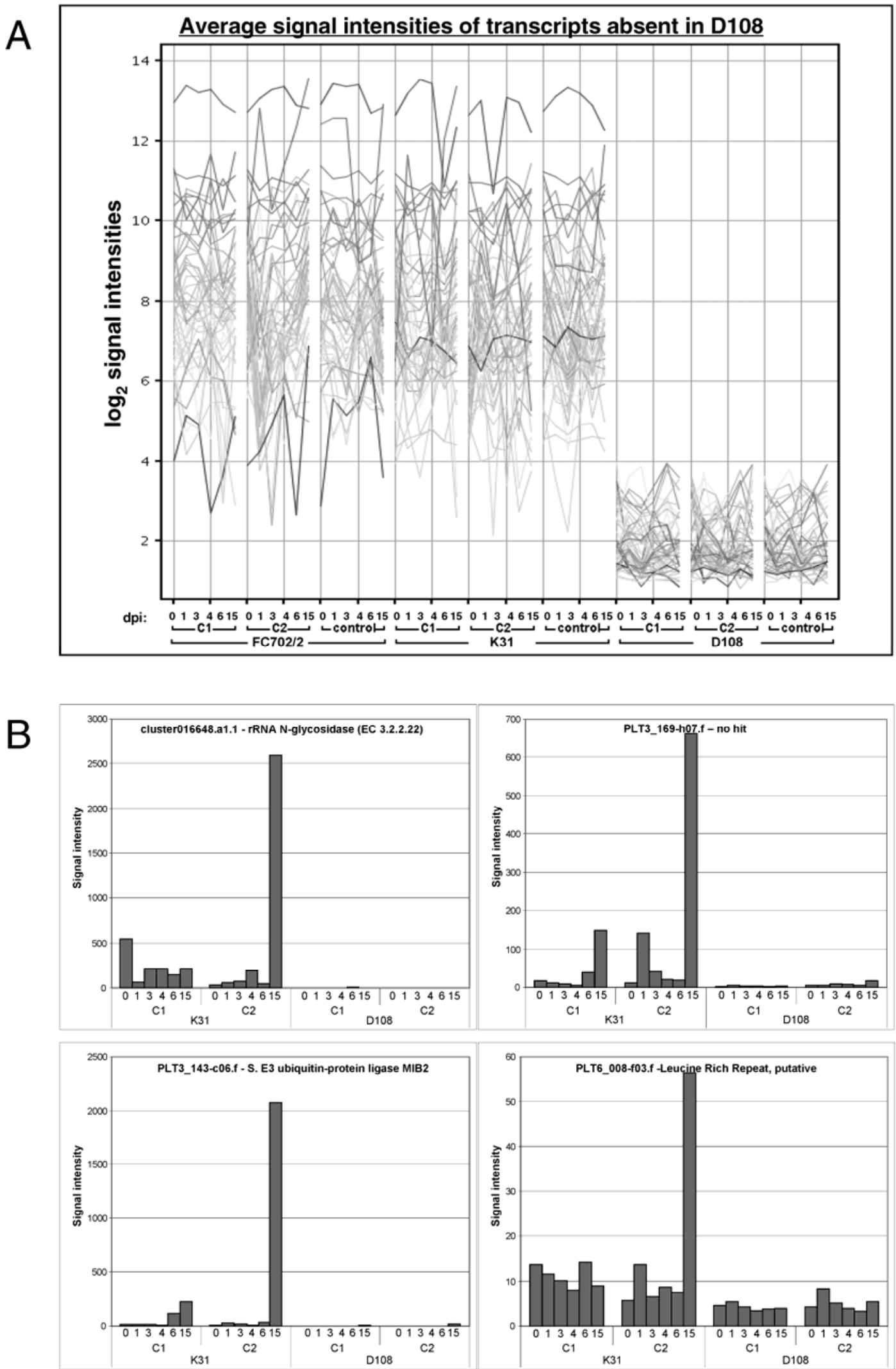

Fig. 5. Cercospora spp.-induced transcripts absent in the susceptible genotype D108 A, K-means clustering identified a group of expression profiles that represented genes absent or only weakly expressed in genotype D108 but highly expressed in the other genotypes. K-means clustering was performed on quantile-normalized baseline-transformed average signal intensities, and genes with normalized log intensities $>4$ in any sample of genotype D108 were removed. Below the plot, the days postinoculation (dpi), pathogen treatment, and genotype are indicated. Each line represents a single transcript. B, Expression profiles of four Cercospora beticola-induced transcripts from K31 with absent or only weak expression in the susceptible genotype D108. The genes were identified by applying the following filters: $t$ test unpaired (K31, C2, d15) versus (K31, control, d15), $P \leq 0.005, \mathrm{FC} \geq 4.0 ; t$ test unpaired (K31, C2, d15) versus (D108, C2, d15), $P \leq 0.01, \mathrm{FC} \geq 10.0$; signal intensity in D108 <25. Below each diagram, dpi, C. beticola isolate, and Beta vulgaris genotype are given. 
considerable differences in the levels of induction. We ranked genes by their fold-change induction after inoculation with isolate $\mathrm{C} 2$, at $1 \mathrm{dpi}$ for $\mathrm{FC} 702 / 2$ and at 15 dpi for $\mathrm{K} 31$ or D108. The 15 genes induced at the highest levels in the monogenic resistant interaction at $1 \mathrm{dpi}$ (median fold change $=19.6$ ) (Table 2) showed much weaker induction in the other interactions (median fold change $=5.9$ for D108 and 7.5 for K31) The same was true vice versa; gene sets from D108 and K31 induced at 15 dpi with median factors of 33.1 or 75.7 were only induced with median factors of 2.1 or 3.1 at 1 dpi in FC702/2. Almost all genes induced to high levels at $1 \mathrm{dpi}$ in the monogenic resistant interaction were involved in cell signaling. In contrast, among the genes induced at the highest levels at 15 dpi in K31 and D108 were the PR genes and genes involved in lignin and alkaloid biosynthesis.

\section{DISCUSSION}

Extensive analysis of plant-pathogen interactions in model plants such as Arabidopsis thaliana has led to research on plant-pathogen interactions of high agronomic importance. Commercial whole-genome arrays of major crop species such as maize, rice, or barley have been employed to analyze transcriptional responses to different pathogens and have contributed significantly to an understanding of the respective plantpathogen interactions (Caldo et al. 2004; Doehlemann et al. 2008; Yang et al. 2006).

Because no commercial microarrays have been available for B. vulgaris, the only previous expression profiling studies involved custom-made cDNA macroarrays for the analysis of sugar beet development. The germination of sugar beet seed

\section{Inoculation with isolate $\mathrm{C2}$}

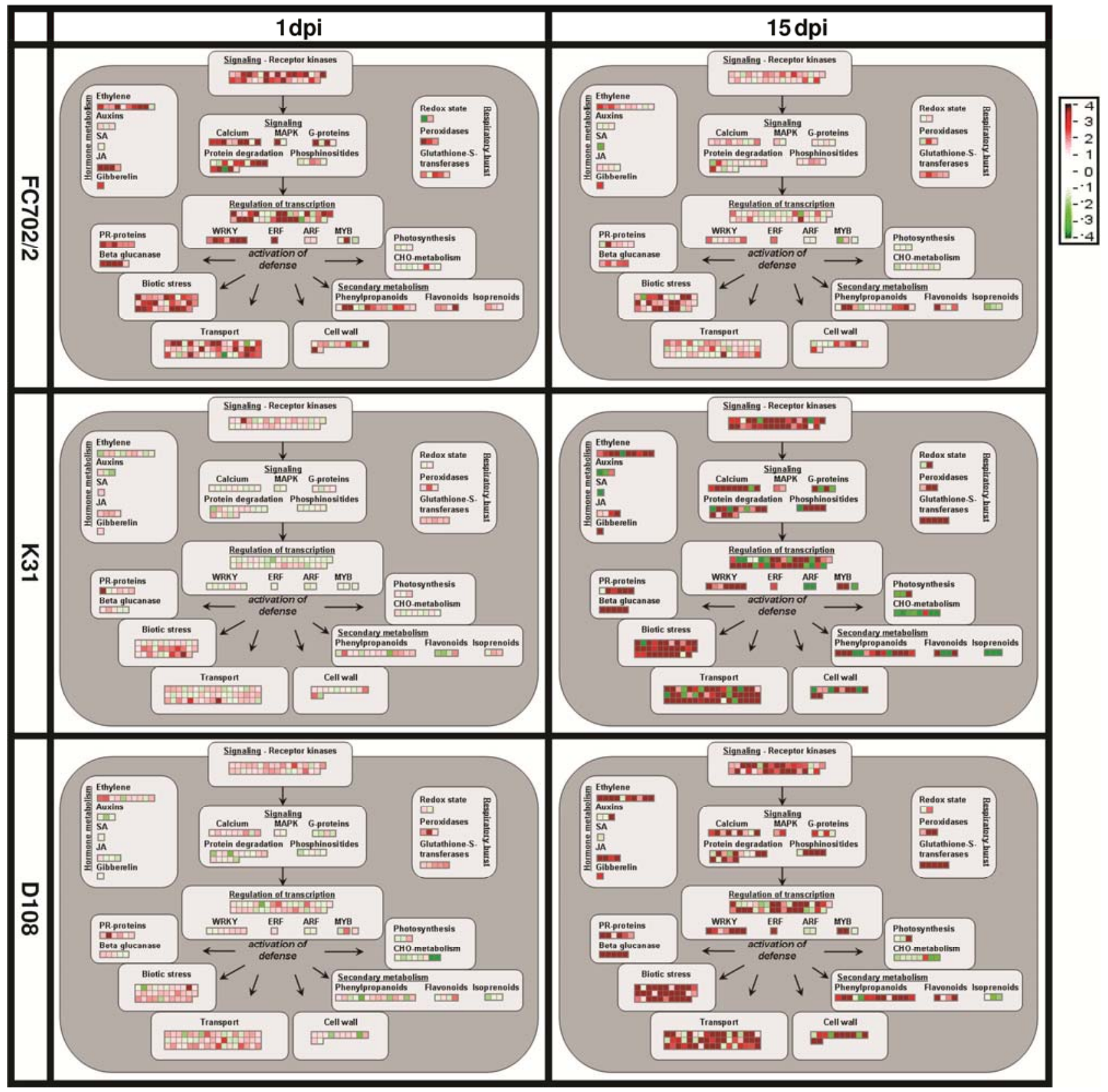

Fig. 6. MapMan-rendered visualization of functional classes of differentially expressed genes. Functional classes over-represented among differentially expressed genes were determined, and an overview map containing these classes was generated with MapMan. Fold-change values are displayed for genes differentially expressed at either 1 or 15 days postinoculation (dpi) with isolate $\mathrm{C} 2$. 
(Pestsova et al. 2008) and the developmental process of sugar beet roots (Bellin et al. 2007) were described with cDNA clones of 2,251 and 11,520 unique genes, respectively. Here, we described the creation of an oligonucleotide-based microarray with the ability to detect 17,277 unique transcripts. With this microarray, we tracked transcriptional responses during the entire infection process of $C$. beticola. Our results showed that monogenic resistance is associated with an early defense response at $1 \mathrm{dpi}$, whereas the other interactions display late defense responses (15 dpi). Further, polygenic partial resistance is associated with a stronger defense response than the susceptible interaction.

\section{Polygenic partial resistance.}

Polygenic resistance typically relies on transmembrane pattern recognition receptors that respond to slowly evolving mi- crobial- or pathogen-associated molecular patterns (PAMPs) that can trigger immunity (PTI). However, pathogens have developed strategies to suppress PTI. Recently, we showed that the phytohormone abscissic acid (ABA) accumulates at the infection site of $C$. beticola (Schmidt et al. 2008). ABA acts as a repressor of phenylalanine ammonia lyase gene expression in sugar beet and is expected to generally suppress defense responses. Further, pathogens can secrete effector molecules into the host cells that suppress defense responses. Indeed, we observed no significant defense responses in the early to midstages of infection in the polygenic resistant or susceptible genotype. Thus, our data support the model that $C$. beticola damps the PTI of sugar beet.

Partial resistance to $C$. beticola in sugar beet is quantitatively inherited and can limit the rate of disease development (Rossi et al. 1999; Smith and Gaskill 1970). The sugar beet genotype

Table 2. Differentially expressed genes for three Beta vulgaris genotypes ${ }^{\mathrm{a}}$

\begin{tabular}{|c|c|c|c|c|}
\hline \multirow[b]{2}{*}{ Genotype, ID $^{\mathrm{c}}$} & \multicolumn{3}{|c|}{ Ratiob $^{\mathbf{b}}$} & \multirow[b]{2}{*}{ Closest ortholog ${ }^{d}$} \\
\hline & FC702/2 d01 & K31 d15 & D108 d15 & \\
\hline \multicolumn{5}{|l|}{ FC702/2 } \\
\hline cluster012814.a1.1 & $100.7 *$ & 5.9 & 7.5 & Putative nuclease HARBI1; Homo sapiens \\
\hline cluster016011.a1.1 & $44.1 *$ & $8.3^{*}$ & $8.2 *$ & RING-H2 finger protein ATL4G; Arabidopsis thaliana \\
\hline cluster016526.a1.1 & $30.6 *$ & $16.9 *$ & $12.7 *$ & Myb-related protein Myb4; Oryza sativa subsp. japonica \\
\hline cluster053825.a1.1 & $24.1 *$ & $9.5^{*}$ & $9.4 *$ & No hit \\
\hline cluster016393.a1.1 & 22.6 & 2.8 & $3.9 *$ & Dehydration-responsive element-binding protein 1D; $A$. thaliana \\
\hline cluster015794.a1.1 & $21.4 *$ & $8.3^{*}$ & $14.2 *$ & U-box domain-containing protein $22 ;$ A. thaliana \\
\hline cluster029196.a1.1 & $20.5 *$ & $7.1^{*}$ & 2.0 & Probable protein phosphatase $2 \mathrm{C} 32 ; O$. sativa subsp. japonica \\
\hline cluster003647.a1.2 & $19.6 *$ & $7.5^{*}$ & $5.9 *$ & Zinc finger protein $1 ;$ Triticum aestivum \\
\hline cluster017307.a1.1 & $18.8 *$ & $5.9 *$ & 1.9 & Probable protein phosphatase $2 \mathrm{C} 32 ; O$. sativa subsp. japonica \\
\hline cluster008376.a1.1 & $18.5^{*}$ & $10.6^{*}$ & 8.7 & Probable WRKY transcription factor 41 ; A. thaliana \\
\hline uni_028-J03.f & 16.9 & $12.6^{*}$ & $14.2 *$ & Pleiotropic drug resistance protein $1 ;$ Nicotiana tabacum \\
\hline PLT6_036-f11.f & $16.2 *$ & 3.6 & 2.0 & Probable WRKY transcription factor 41 ; A. thaliana \\
\hline cluster000433.a1.1 & $16.1 *$ & $6.3^{*}$ & 4.3 & CCR4-NOT transcription complex subunit 7; Bos taurus \\
\hline cluster013860.a1.1 & $14.6 *$ & 4.1 & $5.8^{*}$ & Scarecrow-like protein $14 ;$ A. thaliana \\
\hline cluster006685.a1.1 & $14.2 *$ & 10.4 & $4.2 *$ & ADP-ribosylation factor GTPase-activating protein AGD11; A. thaliana \\
\hline \multicolumn{5}{|r|}{ 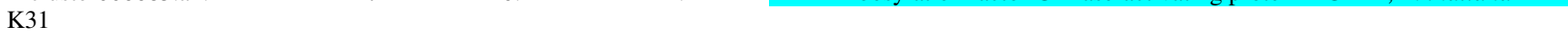 } \\
\hline PLT3_136-e10.r & 1.5 & $214.1 *$ & 16.3 & No hit \\
\hline cluster022303.a1.1 & 0.5 & $195.6 *$ & $63.9 *$ & 18-kDa seed maturation protein; Glycine $\max$ \\
\hline cluster000213.a1.1 & 1.4 & $182.9 *$ & $47.8 *$ & PR protein $1 \mathrm{C}$ precursor; $N$. tabacum \\
\hline cluster000213.a1.2 & 3.7 & $104.0 *$ & $29.1 *$ & PR protein PR-1 type precursor; Sambucus nigra \\
\hline cluster016567.a1.1 & 0.9 & $100.3 *$ & $38.8 *$ & Cytochrome P450 71B10; A. thaliana \\
\hline cluster029293.a1.667 & 2.8 & $90.5 *$ & $42.0 *$ & PR protein R major form precursor; $N$. tabacum \\
\hline PLT3_169-f11.f & 3.4 & $81.1 *$ & $47.8 *$ & No hit \\
\hline PLT6_005-a01.f & 4.0 & $75.7 *$ & $34.8 *$ & Reticuline oxidase precursor; Eschscholzia californica \\
\hline PLT3_125-a08.f & 0.8 & $71.1 *$ & 9.2 & No hit \\
\hline PLT6_010-b05.f & 4.8 & $65.9 *$ & $26.4^{*}$ & 3'-Hydroxy- $N$-methyl- $(S)$-coclaurine 4'-O-methyltransferase; Coptis japonica \\
\hline cluster001299.a1.1 & 1.7 & $62.7 *$ & $33.1 *$ & Basic form of PR protein 1 precursor; N. tabacum \\
\hline cluster016000.a1.1 & 1.4 & $60.9 *$ & $28.2 *$ & 3'-Hydroxy- $N$-methyl- $(S)$-coclaurine 4'- $O$-methyltransferase; $C$. japonica \\
\hline cluster004092.a1.1 & 1.5 & $58.7 *$ & $41.1 *$ & Thaumatin-like protein precursor; Actinidia deliciosa \\
\hline PLT3_125-d04.f & $5.3 *$ & $49.3 *$ & $27.1 *$ & Probable WRKY transcription factor 40; A. thaliana \\
\hline PLT3_105-h07.f & 4.2 & 49.1 & $26.1 *$ & WRKY transcription factor $18 ;$ A. thaliana \\
\hline \multicolumn{5}{|r|}{ 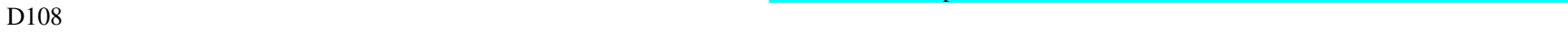 } \\
\hline cluster022303.a1.1 & 0.5 & $195.6 *$ & 63.9* & 18-kDa seed maturation protein; G. $\max$ \\
\hline cluster010495.a1.1 & 1.3 & $21.3 *$ & $63.7 *$ & Acidic mammalian chitinase precursor; B. taurus \\
\hline cluster000213.a1.1 & 1.4 & $182.9 *$ & 47.8* & PR protein $1 \mathrm{C}$ precursor; $N$. tabacum \\
\hline PLT3_169-f11.f & 3.4 & $81.1^{*}$ & 47.8* & No hit \\
\hline cluster029293.a1.667 & 2.8 & $90.5^{*}$ & 42.0* & PR protein R major form precursor; $N$. tabacum \\
\hline cluster004092.a1.1 & 1.5 & $58.7 *$ & 41.1* & Thaumatin-like protein precursor; $A$. Deliciosa \\
\hline PLT3_080-F01.r & 1.2 & $35.3 *$ & 40.1* & Reticuline oxidase-like protein; precursor; $A$. thaliana \\
\hline cluster016567.a1.1 & 0.9 & $100.3 *$ & 38.8* & Cytochrome P450 71B10 A. thaliana \\
\hline PLT6_005-a01.f & 4.0 & $75.7 *$ & 34.8* & Reticuline oxidase precursor; $E$. californica \\
\hline cluster001299.a1.1 & 1.7 & $62.7 *$ & $33.1 *$ & Basic form of PR protein 1 precursor; $N$. tabacum \\
\hline cluster012533.a1.1 & 1.5 & $34.4 *$ & $32.6 *$ & Cytochrome P450 71D11 fragment; Lotus japonicus \\
\hline PLT6_005-c10.f & 1.5 & 10.1 & $29.4 *$ & No hit \\
\hline cluster000213.a1.2 & 3.7 & $104.0 *$ & $29.1 *$ & PR protein PR-1 type precursor; $S$. nigra \\
\hline cluster013646.a1.1 & 3.7 & 2.7 & $28.9 *$ & Cytochrome P450 76C4; A. thaliana \\
\hline cluster016810.a1.1 & 1.7 & $37.5^{*}$ & $28.4 *$ & Trans-cinnamate 4-monooxygenase; Pisum sativum \\
\hline
\end{tabular}


K31 exhibited an increased, polygenic resistance compared with the susceptible genotype D108 in field tests (D. Stahl, unpublished data). Accordingly, K31 samples contained less Cercospora biomass than did the susceptible genotype at $15 \mathrm{dpi}$.

Generally, expression profiles were highly similar for both the K31 and the D108 genotypes after infection with $C$. beticola isolates $\mathrm{C} 1$ or $\mathrm{C} 2$. However, we did identify differences in gene expression that might help to explain the increased resistance of K31. Although $C$. beticola biomass was reduced in the polygenic resistant $\mathrm{K} 31$ genotype, the induction factors in this genotype were, on average, twofold higher than in the susceptible interaction. Further, this genotype exhibited $>1.5$-fold more differentially expressed genes than the susceptible genotype D108. Therefore, the partially resistant genotype appeared to be able to mount a stronger response in the late phase of the infection process than the susceptible genotype.

Many genes that were not or only weakly expressed in D108 were expressed at significantly higher levels in K31. Among these, we found homologs of genes known to be involved in plant pathogen defense. Some of them showed high inducibility by $C$. beticola, as exemplified by a ribosome-inactivating protein (RIP). RIP have N-glycosidase activity; they remove an adenine residue from $28 \mathrm{~S}$ rRNA, which results in the inhibition of protein elongation. Plant RIP can inactivate foreign eukaryotic ribosomes, such as those of fungi, and their antifungal activity has been demonstrated in an in vitro assay (Leah et al. 1991) and in transgenic plants (Corrado et al. 2005; Logemann et al. 1992 ). The question of other enzyme activities of RIP is still unclear. Some plant RIP have been reported to have superoxide dismutase activity, as reviewed by Stirpe and Batelli (2006). Cercosporin, the Cercospora toxin, produces singlet oxygen species and superoxide anions to necrotize the plant cells. These findings have led to the hypothesis that the B. vulgaris RIP (BvRIP) could additionally serve as an antioxidant enzyme, which might explain why a strong expression of BvRIP has been observed at the necrotrophic phase. The expression of additional pathogen-related proteins might contribute to the observed increased resistance. Constitutive and enhanced expression of PR protein genes has resulted in transgenic plants with increased fungal resistance (Alexander et al. 1993; Broglie et al. 1991; Jach et al. 1995; Yoshikawa et al. 1993; Zhu et al. 1994).

Apart from genes acting directly against pathogens, many genes involved in signal perception and cell signaling, such as a receptor-like protein (RLP) and a ubiquitin ligase, were expressed at significantly higher levels in K31 than in D108. RLP are cell-surface receptors that contain extracellular LRR (eLRR) and a short cytoplasmic tail linked by a single transmembrane motif. The eLRR domain is generally thought to mediate ligand perception. RLP differ from RLK in that they lack the cytoplasmic kinase domain. A genome-wide functional analysis of the roles of the 57 RLP in A. thaliana revealed that the surface receptors are involved in plant growth, plant development, and sensitivity to abiotic and biotic stress (Wang et al. 2008). Furthermore, RLP play important roles in plant innate immunity of crops. RLP are one class of R proteins in plants in addition to the two classes of RLK and nucleotide-binding site LRR proteins (Dangl and Jones 2001). The-best analyzed RLP-type resistance $(\mathrm{R})$ proteins are the $\mathrm{Cf}$ and Ve proteins of tomato (Solanum lycopersicum) and the HcrVf2 protein of apple (Malus domestica). These $\mathrm{R}$ proteins confer resistance against the fungal pathogens Cladosporium fulvum, Verticillium spp., and Venturia inaequalis (Belfanti at al. 2004; Fradin et al. 2009; Jones et al. 1994). Two pattern-recognition receptors for fungal PAMPs have been identified in tomato. Perception of the ethylene-inducing xylanase (EIX) requires the RLP LeEIX1 and LeEIX2 (Ron and Avni 2004). Thus, we propose a model in which the specific or increased expression of proteins involved in PAMP perception and cell signaling processes gives rise to the stronger defense response observed in the partially resistant genotype $\mathrm{K} 31$. It is easy to imagine that the presence of additional or more abundant receptors or downstream signaling components might facilitate better pathogen recognition or signal transduction and, thus, increase polygenic resistance. Our observations of the differences between the expression profiles of the polygenic resistant and susceptible sugar beet genotypes support recent reports suggesting that defense-responsive and receptor-type genes are important resources for polygenic resistance (Kou and Wang 2010).

Under disease-free conditions, polygenic resistant cultivars produce lower yields compared with susceptible cultivars, despite the extensive breeding efforts invested in the development of cultivars with high yield and high resistance (Holtschulte et al. 2010; Mechelke 2000). This failure could be attributed to the difficulties in selecting several resistance loci without losing yield performance. Alternatively, the induced or permanent activation of defense responses and the production of PR proteins might consume resources that are normally dedicated to increasing yield ("cost of fitness"). We observed reduced expression levels of putative defense genes in the higher-yielding, susceptible genotype D108 compared with the polygenic resistant genotype K31. High expression of these defense genes might have been lost in the susceptible genotype during breeding for increased yield.

\section{Monogenic resistance (gene-for-gene resistance).}

In contrast to polygenic resistance, monogenic resistance is characterized by gene-for-gene dependence, where there is a matched specificity between a plant disease $R$ gene and a pathogen Avr gene (Jones and Dangl 2006). Although pathogens can use effector proteins to suppress PTI, in gene-for-gene resistance, dominant $R$ genes that encode proteins that recognize pathogen effectors can establish an effector-triggered immunity (ETI).

In this study, we demonstrated that monogenic resistance of genotype FC702/2 was associated with a defense response that occurred only 1 dpi whereas, at $15 \mathrm{dpi}$, differential gene expression was almost undetectable. This response was unexpectedly rapid compared with the much slower responses in polygenic resistance. In BLAST annotations of the 32 genes that showed the strongest induction, we found five genes annotated as homologs of the rapidly elicited Avr9/Cf-9 proteins in Nicotiana tabacum (Durrant et al. 2000). These genes are known to be induced in gene-for-gene resistance.

Despite the extreme temporal differences between transcriptional defense responses, the sets of regulated genes in monogenic and polygenic resistance were surprisingly similar. This similarity is not a surprise only in the context of the PAMP- or effector-triggered basis of the response; in addition, whereas, at $1 \mathrm{dpi}$, the fungus is still on the leaf surface, after 15 days, it has colonized the leaf parenchyma and switched to a necrotrophic lifestyle. Therefore, this comparison involves two distinct types of interaction.

Furthermore, we might be observing two different stages of a temporal sequence of transcriptional processes that make up part of the defense response, because the analyzed time points are not directly comparable. Almost all genes induced to high levels at $1 \mathrm{dpi}$ in the monogenic resistant interaction were involved in cell signaling. In contrast, among the genes induced at the highest levels at $15 \mathrm{dpi}$ in K31 and D108 were the PR genes and genes involved in lignin and alkaloid biosynthesis. Of interest is the fact that, in the monogenic resistant interaction, PR genes, in particular, reached maximum expression at 3 rather than 1 dpi (Fig. 3). It is possible that the genes involved 
in signaling processes were induced first and that genes with antifungal activity or genes involved in cell wall fortification were induced later.

Using the Mercator and MapMan tools, we identified only a few classes of genes that could clearly differentiate both responses (e.g., the repression of $\mathrm{CHO}$ metabolism or the expression of GST). The repression of photosynthesis genes was absent at $1 \mathrm{dpi}$ in the monogenic resistance and was only observed at $15 \mathrm{dpi}$ in the other interactions. This finding is of interest because a decrease in photosynthesis has been described in compatible and incompatible interactions in other plants (Tao et al. 2003). All five of the GST that were only slightly induced or not induced at $1 \mathrm{dpi}$ in the monogenic resistance interaction showed high levels of induction at $15 \mathrm{dpi}$ in the other interactions. It is tempting to speculate that this induction resulted from the superoxide-forming activity of the necrotizing phytotoxin cercosporin that Cercospora beticola produces.

Six genes were significantly repressed in the monogenic resistance interaction whereas they were induced in the polygenic and susceptible interactions. Among these was an aspartic proteinase gene that is a close homolog of the constitutive disease resistance 1 (CDR1) gene in A. thaliana. CDR1 has been implicated in disease resistance signaling (Simoes et al. 2007).

The functional classification of the differentially regulated B. vulgaris transcripts indicated that SA-regulated genes are less involved in the defense reaction compared with genes under regulation by ethylene and JA. The JA/ethylene pathway is considered to be more important in defending necrotrophic pathogens, and the SA-dependent responses are more effective against biotrophic pathogens (Thomma et al. 2001).

Given the PAMP- or effector-triggered basis of the response, the differences in the form of interaction, and the possibility of two different stages of a temporal sequence of transcriptional processes, greater differences between the two defense responses might be expected. The high similarity we found supports the view that responses mediated by $R$ genes accelerate or amplify PAMP-triggered responses, resulting in transcriptional activation of similar defense-associated genes (Jones and Dangl 2006). Similar results have also been reported for other plant species after infection with virulent or avirulent pathogen isolates ( $\mathrm{Li}$ et al. 2006). However, the temporal differences we observed between defense responses in monogenic and polygenic resistance of $B$. vulgaris were far greater than in other plant-pathogen systems.

The race-specificity and the monogenic origin support the view that the $C b$-mediated resistance is a true gene-for-gene resistance. Current models of gene-for-gene resistance or ETI postulate the action of an effector molecule (AvrCb) secreted only by isolate $\mathrm{C} 2$ that can increase the virulence of this isolate but that triggers ETI on sugar beet cultivars carrying the corresponding $\mathrm{Cb} R$ gene. Consistent with this model, we observed an increased virulence of isolate $\mathrm{C} 2$.

It has to be expected that $C$. beticola secretes effector molecules, as shown for Cladosporium fulvum, a phylogenetically related pathogen with an infection process highly similar to Cercospora beticola (Thomma et al. 2005). However, the research on Cladosporium fulvum has focused on effectors secreted into the apoplast after the fungus has entered the leaf. Strikingly, the transcriptional defense response in the monogenic Cercospora beticola-B. vulgaris interaction had already reached its maximum at $1 \mathrm{dpi}$; thus, the recognition of $C$. beticola is likely to take place soon after the conidia germinate and before the fungus has entered the leaf. If this response is, indeed, triggered by a putative $A v r C b$ gene product, the implication would be that the $A v r C b$ gene product is secreted or passes through the cuticle. However, passing of an AvrCb effector protein through the hydrophobic cuticle is difficult to imagine. The
$A v r C b$ product might also be a small hydrophobic fungal molecule that could already be present in the culture filtrate. To prepare the inoculum, we scratched the mycelium from the agar plates and diluted the mycelium fragments in water. In doing so, we separated the medium from the fungus and, therefore, the elicitor might be associated with the mycelium. This hypothesis could be checked by using heat-killed spores and testing these spores for triggering similar responses.

In summary, this study described the $B$. vulgaris transcriptional defense responses in susceptible, polygenic partially resistant, and monogenic resistant genotypes after $C$. beticola infection. We identified defense-responsive genes and genes involved in signal perception and cell signaling that are associated with polygenic resistance. This work provides an excellent platform for future investigations to enhance the understanding of partial polygenic resistance. Although polygenic resistance is only partial and is weaker than gene-for-gene resistance, it is of great economic interest. Quantitative resistance is expected to be race nonspecific and more durable than qualitative resistance and, therefore, is of special relevance for breeding programs (Boyd 2006). Recent advances in genomics (Varshney et al. 2009) and the identification and application of QTL for fungal resistance in different crops (by marker assisted selection) (Bert et al. 2004; Buerstmayr et al. 2009; Delourme et al. 2008; Kou and Wang 2010; Zwonitzer et al. 2010) have made this approach all the more appealing. Furthermore, future work will have to focus on the identification of $A v r C b$ and on elucidating the mode of its perception by the $\mathrm{Cb}$ gene.

\section{MATERIALS AND METHODS}

Plant and fungal material and inoculation procedure.

Sugar beet (B. vulgaris L.) of the genotypes FC702/2 (Hecker and Gaskill 1972), D108, and K31 (KWS SAAT AG, Einbeck, Germany) were grown in 1-liter pods under greenhouse conditions for approximately 12 weeks before inoculation. The $C$. beticola isolates $\mathrm{C} 1$ (isolate Ahlburg from KWS SAAT AG) and C2 (American Type Culture Collection 24080) were propagated on V8 agar plates for 2 weeks at $25^{\circ} \mathrm{C}$ in the dark. C. beticola infection of the sugar beet lines was performed with 30,000 mycelium fragments per milliliter of isolates $\mathrm{C} 1$ and $\mathrm{C} 2$ in the greenhouse, as previously described (Schmidt et al. 2004).

\section{Microscopic analysis of $C$. beticola growth on infected leaves.}

During the first week after inoculation, leaf disks of inoculated plants were collected. Ten leaf disks per genotype and treatment were stained with aniline blue, as described (Schmidt et al. 2004). Aniline-blue-stained fungal structures were observed under a Zeiss Axioscope microscope (Oberkochen, Germany). The portion of germinated conidia, the stage of hyphal growth, and the rate of stomatal penetration were counted and recorded.

\section{Microarray design process, sample preparation, and microarray hybridization.}

cDNA clones were isolated from untreated and $C$. beticolainfected sugar beet leaves. The normalized cDNA libraries KWS3 of the susceptible genotype KWS2320 and KWS6 of the C. beticola-resistant genotype K31 were created from RNA sampled at 4, 7, and 12 days after infection. Nonredundant cDNA clones were isolated with the ofp approach, as described by Herwig and associates (2002). The data analysis yielded 18,528 ofp clusters from library KWS3 and 9,867 ofp clusters from library KWS6. For each cluster, cDNAs were sequenced. After removing duplicate sequences, all ofp clusters from both libraries represented 17,277 different genes. 
A high-resolution microarray with 244,000 60-mer oligos representing the 17,277 genes was constructed, where each oligo had to be a unique tag for the respective cluster sequence. The base composition was designed as suggested by Agilent's eArray software (Agilent, Palo Alto, CA, U.S.A.). The oligo density per cluster was adjusted to be approximately constant for all clusters. The resulting $244 \mathrm{~K}$ microarray was hybridized with a complex pool of sugar beet RNAs labeled with cy3 and fragmented sugar beet genomic DNA labeled with cy5. For labeling, genomic DNA was fragmented by sonication (Biorupter, $2 \times 4 \mathrm{~min}$, high, 30 on, 30 off). Labeling was performed using cyanine-dye-labeled 9-mer primers from TibMolBio.

Oligos were ranked by their filtered signal intensities, and oligos producing intensities that were $<1$ standard deviation from the mean signal per cluster were avoided. When no signal was detected above background with the RNA probes (cy3), the same procedure was applied for the DNA (cy5) probes. Finally, a minimal number of approximately three oligos per cluster was selected for the production of the final $44 \mathrm{~K}$ sugar beet microarray.

Sample preparation protocols were optimized with a subarray that represented 1,500 genes. Total RNA of sugar beet was isolated with the NucleoSpin RNA Plant Kit (Macherey-Nagel, Düren, Germany) according to the manufacturer's instructions. For each time point, four biological replicate samples were prepared in parallel. After RNA isolation, DNAse treatment was performed to digest the remaining genomic DNA. In brief, $60 \mu \mathrm{l}$ of eluted RNA was incubated with $5 \mu$ of DNAse (1 unit $/ \mu \mathrm{l}$ ) in a total volume of $100 \mu \mathrm{l}$ for $60 \mathrm{~min}$ at $37^{\circ} \mathrm{C}$. After the DNAse treatment, a phenol-chloroform extraction was performed, and the RNA was precipitated with ethanol. The RNA was quantified in a fluorometric assay with RiboGreen (Molecular Probes, Göttingen, Germany). The integrity of the total RNA was confirmed on an Agilent 2100 bioanalyzer.

Microarray hybridization was performed as described by the manufacturer (Agilent One-Color Microarray-Based Gene Expression Analysis, version 5.7).

\section{qRT-PCR.}

qRT-PCR was performed with total RNA from sugar beet leaves. Total RNA (1 $\mu \mathrm{g})$ was used to construct first-strand cDNA with the SuperScript First-Strand synthesis system for RT-PCR (Invitrogen GmbH, Karlsruhe, Germany) according the manufacturer's instructions. qRT-PCR was performed with the Applied Biosystems StepOne real-time PCR system and the Power SYBR Green PCR Master Mix (Applied Biosystems, Darmstadt, Germany). The primers for qRT-PCR were as follows: 5'-GAACTTCTCAAAGCCCATGC-3' and 5'-CGAGTTT CGAGGCTATTTGG-3' for PLT3_005-G06.f, 5'-CTCGTTGG GTCCAAAACAAT-3' and 5'-TAGCTGATCGAAGGGCATTT3' for cluster029293.a1.869, 5'-AATCACACTCACCCATGCA A-3' and 5'-ATCATCGCAATCGAGTTTCC-3' for PLT3_012_ d06, 5'-GCAAGTGAAGGGGAGCACGAAT-3' and 5'-GCTTT GGATGGTTGTGACTTCCCT-3' for PLT3_073_f04, and 5'-T CAAATTGACACCTTAGAGGTCCTTGA-3' and 5'-CTTCC AAGTCGTTCCCACTGAAAT-3' for PLT6_008_f03. The absolute target quantity in the samples was determined with the standard curve method according to the manufacturer's instructions. All experiments were performed with three technical replicates.

Results were normalized to the expression of the sugar beet gene PLT3_075_F09, amplified with the primers 5'-GAGGAA CTAGACATGGGGATACAT-3' and 5'-GCGATACAAAGTAG ACATTAGAACTC-3'. The gene PLT3_075_F09 encodes an unknown protein but it has been identified as a constitutively expressed gene in different sugar beet genotypes. This gene was found to be constitutively expressed during different time points of fungal infection in the presented microarray analysis of sugar beet. Negative control wells that contained the reaction mixture with water as template were included on each plate.

\section{Analysis of global gene expression data.}

Gene signal intensities were calculated as the median of the corresponding oligo signal intensities. Expression data were further analyzed by importing gene signal intensities into GeneSpring GX 10.0 (Silicon Genetics; Agilent Technologies). Signal intensities for all arrays were quantile normalized. For statistical analysis, data were log-transformed. To identify differentially expressed genes, the fold change values were calculated based on the ratio between the mean signal intensities of the respective replicate groups. Statistical significance was calculated by $t$ tests. The number of genes with differential expression was determined by an absolute fold change $>3$ and a $P$ value $<0.001$. Venn diagrams were calculated with Excel. PCA and hierarchical clustering were performed on the signal intensities of all entities present on the sugar beet $44 \mathrm{~K}$ array. Hierarchical clustering was performed with squared Euclidean as a similarity measure and centroid as a linkage rule. For Cercospora biomass estimation, transcripts represented on the $44 \mathrm{~K}$ array were determined to originate from Cercospora spp. when the five highest-scoring homologs (blastp analysis against UniProt; blastp 2.2.13) (Altschul et al. 1997) belonged to the phylum Ascomycota.

\section{MapMan.}

The transcripts represented on the $44 \mathrm{~K}$ sugar beet array were functionally categorized for MapMan with the Mercator tool. The $P$ value for over-representation of functional classes was estimated with the hypergeometric distribution as a cumulative probability of each single category, drawing from the population of total genes in that category that were represented on the entire microarray. Calculations were performed with Excel.

\section{ACKNOWLEDGMENTS}

We thank B. Ahlswede, S. Klages-Ahlswede, J. Kurrasch, and W. Brieß for excellent technical assistance in the performance of the resistance assays and the microscopic analysis; and B. Usadel at the Max Planck Institute of Molecular Plant Physiology (Potsdam-Golm, Germany) for support in adapting the MapMan tool to sugar beet profiling data.

\section{LITERATURE CITED}

Alexander, D., Goodman, R. M., Gut-Rella, M., Glascock, C., Weymann, K., Friedrich, L., Maddox, D., Ahl-Goy, P., Luntz, T., Ward, E., and Ryals, J. 1993. Increased tolerance to two oomycete pathogens in transgenic tobacco expressing pathogenesis-related protein 1a. Proc. Natl. Acad. Sci. U.S.A. 90:7327-7331.

Altschul, S. F., Madden, T. L., Schaffer, A. A., Zhang, J., Zhang, Z., Miller, W., and Lipman, D. J. 1997. Gapped BLAST and PSI-BLAST: A new generation of protein database search programs. Nucleic Acids Res. 25:3389-3402.

Belfanti, E., Silfverberg-Dilworth, E., Tartarini, S., Patocchi, A., Barbieri, M., Zhu, J., Vinatzer, B. A., Gianfranceschi, L., Gessler, C., and Sansavini, S. 2004. The HcrVf2 gene from a wild apple confers scab resistance to a transgenic cultivated variety. Proc. Natl. Acad. Sci. U.S.A 101:886-890

Bellin, D., Schulz, B., Soerensen, T. R., Salamini, F., and Schneider, K. 2007. Transcript profiles at different growth stages and tap-root zones identify correlated developmental and metabolic pathways of sugar beet. J. Exp. Bot. 58:699-715.

Benjamini, Y., and Hochberg, Y. 1995. Controlling the false discovery rate: A practical and powerful approach to multiple testing. J. R. Stat. Soc. Ser. B 57:300.

Bert, P.-F., Dechamp-Guillaume, G., Serre, F., Jouan, I., Tourvieille de Labrouhe, D. , Nicolas, P., and Vear, F. 2004. Comparative genetic analy- 
sis of quantitative traits in sunflower (Helianthus annuus L.) 3. Characterisation of QTL involved in resistance to Sclerotinia sclerotiorum and Phoma macdonaldi. Theor. Appl. Genet. 109:865-874.

Boyd, L. A. 2006. Can the durability of resistance be predicted? J. Sci. Food Agric. 86:2523-2526

Broglie, K., Chet, I., Hollidat, M., Cressman, R., Biddle, P., Knowlton, S. Mauvais, C. J., and Broglie, R. 1991. Transgenic plants with enhanced resistance to the fungal pathogen Rhizoctonia solani. Science 254:11941197.

Buerstmayr, H., Ban, T., and Anderson, J. A. 2009. QTL mapping and marker- assisted selection for Fusarium head blight resistance in wheat: A review. Plant Breed. 128:1-26.

Caldo, R. A., Nettleton, D., and Wise, R. P. 2004. Interaction-dependent gene expression in Mla-specified response to barley powdery mildew. Plant Cell 16:2514-2528.

Corrado, G., Delli Bovi, P., Ciliento, R., Gaudio, L., Di Maro, A., Aceto, S., Lorito, M., Rao, R. 2005. Inducible expression of a Phytolacca heterotepala ribosome-inactivating protein leads to enhanced resistance against major fungal pathogens in tobacco. Phytopathology 95:206-215.

Dangl, J. L., and Jones, J. D. 2001. Plant pathogens and integrated defence responses to infection. Nature 411:826-833.

Daub, M. E., and Ehrenshaft, M. 2000. The photoactivated Cercospora toxin cercosporin: Contributions to plant disease and fundamental biology. Annu. Rev. Phytopathol. 38:461-490.

Delourme, R., Piel, N., Horvais, R., Pouilly, N., Domin, C., Vallée, P., Falentin, C., Manzanares-Dauleux. M. J., and Renard, M. 2008. Molecular and phenotypic characterization of near isogenic lines at QTL for quantitative resistance to Leptosphaeria maculans in oilseed rape (Brassica napus L.). Theor. Appl. Genet. 117:1055-1067.

Doehlemann, G., Wahl, R., Horst, R. J., Voll, L. M., Usadel, B., Poree, F. Stitt, M., Pons-Kuhnemann, J., Sonnewald, U., Kahmann, R., and Kamper, J. 2008. Reprogramming a maize plant: Transcriptional and metabolic changes induced by the fungal biotroph Ustilago maydis. Plant J. 56:181-195.

Durrant, W. E., Rowland, O., Piedras, P., Hammond-Kosack, K. E., and Jones, J. D. 2000. cDNA-AFLP reveals a striking overlap in race-specific resistance and wound response gene expression profiles. Plant Cell 12:963-977.

Feindt, F., Mendgen, K., and Heitefuss, R. 1981. Feinstruktur unterschiedlicher Zellwandreaktionen im Blattparenchym anfälliger und resistenter Rüben (Beta vulgaris L.) nach Infektion durch Cercospora beticola Sacc. Phytopathol. Z. 101:248-264.

Fradin, E. F., Zhang, Z., Juarez Ayala, J. C., Castroverde, C. D., Nazar, R. N., Robb, J., Liu, C. M., and Thomma, B. P. 2009. Genetic dissection of Verticillium wilt resistance mediated by tomato Ve1. Plant Physiol. 150:320-332.

Frishman, D., Albermann, K., Hani, J., Heumann, K., Metanomski, A., Zollner, A., and Mewes, H. W. 2001. Functional and structural genomics using PEDANT. Bioinformatics 17:44-57.

Gottschalk, T. E., Mikkelsen, J. D., Nielsen, J. E., Nielsen, K. K., and Brunstedt, J. 1998. Immunolocalization and characterization of a [beta]1,3-glucanase from sugar beet, deduction of its primary structure and nucleotide sequence by cDNA and genomic cloning. Plant Sci. 132:153.

Goudet, C., Very, A. A., Milat, M. L., Ildefonse, M., Thibaud, J. B., Sentenac, H., and Blein, J. P. 1998. Magnesium ions promote assembly of channel-like structures from beticolin 0, a non-peptide fungal toxin purified from Cercospora beticola. Plant J. 14:359-364.

Hecker, R. J., and Gaskill, J. O. 1972. Registration of FC 701 and FC 702 sugarbeet germplasm. Crop Sci. 12:400.

Herwig, R., Schulz, B., Weisshaar, B., Hennig, S., Steinfath, M. Drungowski, M., Stahl, D., Wruck, W., Menze, A., O’Brien, J., Lehrach, H., and Radelof, U. 2002. Construction of a 'unigene' cDNA clone set by oligonucleotide fingerprinting allows access to 25000 potential sugar beet genes. Plant J. 32:845-857

Holtschulte, B., Mechelke, W., and Stahl, D. 2010. Conventional and novel approaches in breeding for resistance to Cercospora beticola in sugar beet. Pages 129-141 in: Cercospora Leaf Spot of Sugar Beet and Related Species. R. T. Lartey, J. J. Weiland, L. Panella, P. W. Crous, and C. E. Windels, eds. The American Phytopathological Society. St. Paul, Minnesota, U.S.A.

Jach, G., Gornhardt, B., Mundy, J., Logemann, J., Pinsdorf, E., Leah, R., Schell, J., and Maas, C. 1995. Enhanced quantitative resistance against fungal disease by combinatorial expression of different barley antifungal proteins in transgenic tobacco. Plant J. 8:97-109.

Jones, D. A., Thomas, C. M., Hammond-Kosack, K. E., Balint-Kurti, P. J., and Jones, J. D. 1994. Isolation of the tomato Cf-9 gene for resistance to Cladosporium fulvum by transposon tagging. Science 266:789-793.

Jones, J. D., and Dangl, J. L. 2006. The plant immune system. Nature 444:323-329.

Koch, G., and Jung, C. 2000. Genetic localization of Cercospora resis- tance genes. Adv. Sugar Beet Res. IIRB:197-210.

Kou, Y., and Wang, S. 2010. Broad-spectrum and durability: Understanding of quantitative disease resistance. Curr. Opin. Plant Biol. 13:181-185.

Leah, R., Tommerup, H., Svendsen, I., and Mundy, J. 1991. Biochemical and molecular characterization of three barley seed proteins with antifungal properties. J. Biol. Chem. 266:1564-1573.

Li, C., Bai, Y., Jacobsen, E., Visser, R., Lindhout, P., and Bonnema, G. 2006. Tomato defense to the powdery mildew fungus: Differences in expression of genes in susceptible, monogenic- and polygenic resistance responses are mainly in timing. Plant Mol. Biol. 62:127.

Logemann, J., Jach, G., Tommerup, H., Mundy, J. and Schell, J. 1992. Expression of a barley ribosome-inactivating protein leads to increased fungal protection in transgenic tobacco plants. Nature Biotechnol. 10:305-308.

Mechelke, W. 2000. Züchtungs- und Sortenstrategien zur ResistenZ. bei Zuckerrüben gegenüber Cercospora beticola. Zuckerindustrie 9:688692.

Nielsen, K. K., Mikkelsen, J. D., Kragh, K. M., and Bojsen, K. 1993. An acidic class III chitinase in sugar beet: Induction by Cercospora beticola, characterization, and expression in transgenic tobacco plants. Mol. Plant-Microbe Interact. 6:495-506.

Nilsson, N. O., Hansen, M., Panagopoulos, A. H., Tuvesson, S., Ehlde, M., Christiansson, M., Rading, I. M., Rissler, M., and Kraft, T. 1999. QTL analysis of Cercospora leaf spot resistance in sugar beet. Plant Breed. 118:327-334.

Pestsova, E., Meinhard, J., Menze, A., Fischer, U., Windhovel, A., and Westhoff, P. 2008. Transcript profiles uncover temporal and stress-induced changes of metabolic pathways in germinating sugar beet seeds. BMC Plant Biol. 8:122.

Rathaiah, Y. 1977. Stomatal tropism of Cercospora beticola in sugarbeet. Phytopathology 67:358-362.

Ron, M., and Avni, A. 2004. The receptor for the fungal elicitor ethyleneinducing xylanase is a member of a resistance-like gene family in tomato. Plant Cell 16:1604-1615.

Rossi, V., Giosue, S., and Racca, P. 1999. A model integrating components of rate-reducing resistance to Cercospora leaf spot in sugar beet. J. Phytopathol. 147:339-346.

Schäfer-Pregl, R., Borchardt, D. C., Barzen, E., Glass, C., Mechelke, W., Seitzer, J. F., and Salamini, F. 1999. Localization of QTLs for tolerance to Cercospora beticola on sugar beet linkage groups. Theor. Appl. Genet. 99:829.

Schmidt, K., Heberle, B., Kurrasch, J., Nehls, R., and Stahl, D. J. 2004. Suppression of phenylalanine ammonia lyase expression in sugar beet by the fungal pathogen Cercospora beticola is mediated at the core promoter of the gene. Plant Mol. Biol. 55:835-852.

Schmidt, K., Pflugmacher, M., Klages, S., Maser, A., Mock, A., and Stahl, D. J. 2008. Accumulation of the hormone abscisic acid (ABA) at the infection site of the fungus Cercospora beticola supports the role of ABA as a repressor of plant defence in sugar beet. Mol. Plant Pathol. 9:661-673.

Setiawan, A., Koch, G., Barnes, S. R., and Jung, C. 2000. Mapping quantitative trait loci (QTLs) for resistance to Cercospora leaf spot disease (Cercospora beticola Sacc.) in sugar beet (Beta vulgaris L.). Theor. Appl. Genet. 100:1176.

Simoes, I., Faro, R., Bur, D., and Faro, C. 2007. Characterization of recombinant CDR1, an Arabidopsis aspartic proteinase involved in disease resistance. J. Biol. Chem. 282:31358-31365.

Smith, G. A., and Gaskill, J. O. 1970. Inheritance of resistance to Cercospora leaf spot in sugarbeet. J. Am. Soc. Sugarbeet Technol. 16:172-180.

Smith, G. A., and Ruppel, E. G. 1974. Heritability of resistance to Cercospora leaf spot in sugarbeet. Crop Sci. 14:113-115.

Steinkamp, M. P., Martin, S. S., Hoefert, L. L., and Ruppel, E. G. 1979. Ultrastructure of lesions produced by Cercospora beticola in leaves of Beta vulgaris. Physiol. Plant Pathol. 15:13.

Stirpe, F., and Batelli, M. G. 2006. Ribosome-inactivating proteins: Progress and problems. Cell. Mol. Life Sci. 63:1850-1866.

Tao, Y., Xie, Z., Chen, W., Glazebrook, J., Chang, H. S., Han, B., Zhu, T., Zou, G., and Katagiri, F. 2003. Quantitative nature of Arabidopsis responses during compatible and incompatible interactions with the bacterial pathogen Pseudomonas syringae. Plant Cell 15:317-330.

Thimm, O., Blasing, O., Gibon, Y., Nagel, A., Meyer, S., Kruger, P., Selbig, J., Muller, L. A., Rhee, S. Y., and Stitt, M. 2004. MAPMAN: A userdriven tool to display genomics data sets onto diagrams of metabolic pathways and other biological processes. Plant J. 37:914-939.

Thomma, B. P., Penninckx, I. A., Broekaert, W. F., and Cammue, B. P. 2001. The complexity of disease signaling in Arabidopsis. Curr. Opin. Immunol. 13:63-68.

Thomma, B. P. H. J., van Esse, H. P., Crous, P. W., and de Wit, P. J. G. M. 2005. Cladosporium fulvum (syn. Passalora fulva), a highly specialized plant pathogen as a model for functional studies on plant pathogenic 
Mycosphaerellaceae. Mol. Plant Pathol. 6:379-393.

Varshney R. K., Nayak S. N., May G. D., and Jackson S. A. 2009. Nextgeneration sequencing technologies and their implications for crop genetics and breeding. Trends Biotechnol. 27:522-530.

Wang, G., Ellendorff, U., Kemp, B., Mansfield, J. M., Forsyth, A., Mitchell, K., Bastas, K., Liu, C.-M., Woods-Tor, A., Zipfel, C., de Wit, P. J. G. M., Jones, J. D. G., Tor, M., and Thomma, B. P. H. J. 2008. A genome-wide functional investigation into the roles of receptor-like proteins in Arabidopsis. Plant Physiol. 147:503-517.

Whitney, E. D., and Lewellen, R. T. 1976. Identification and distribution of races $\mathrm{C} 1$ and $\mathrm{C} 2$ of Cercospora beticola from sugarbeet. Phytopathology 66:1158-1160.

Wise, R. P., Moscou, M. J., Bogdanove, A. J., and Whitham, S. A. 2007. Transcript profiling in host-pathogen interactions. Annu. Rev. Phytopathol. 45:329-369.

Yang, B., Sugio, A., and White, F. F. 2006. Os8N3 is a host disease-susceptibility gene for bacterial blight of rice. Proc. Natl. Acad. Sci. U.S.A. 103:10503-10508.
Yoshikawa, M., Tsuda, M., and Takeuchi, Y. 1993. Resistance to fungal diseases in transgenic tobacco plants expressing the phytoalexin elicitor-releasing factor, $\beta$-1,3-endoglucanase, from soybean. Naturwissenschaften 80:417-420.

Zhu, Q., Maher, E. A., Masoud, S., Dixon, R. A., and Lamb, C. J. 1994. Enhanced protection against fungal attack by constitutive co-expression of chitinase and glucanase genes in transgenic tobacco. Biotechnology 12:807-812.

Zwonitzer, J. C., Coles, N. D., Krakowsky, M. D., Arellano, C., Holland, J. B., McMullen, M. D., Pratt, R. C., and Balint-Kurti, P. J. 2010. Mapping resistance quantitative trait loci for three foliar diseases in a maize recombinant inbred line population-evidence for multiple disease resistance? Phytopathology 100:72-79.

\section{AUTHOR-RECOMMENDED INTERNET RESOURCE}

MapMan Mercator website: mapman.gabipd.org/web/guest/app/mercator 